\title{
Can Vaginal Hysterectomy be Left for the Treatment of Advanced Stage of Pelvic Organ Prolapse?
}

\begin{abstract}
Keywords: Hysterectomy; Vaginal; Pelvic organ prolapse; Cystocele; Rectocele; Mesh; surgic al

Abstract

Pelvic organ prolapse is the downward descent of female pelvic organs, including the bladder, uterus or post-hysterectomy vagina cuff, and the small or large bowel, resulting in protrusion of the vagina, uterus, or both. Prolapse development is multifactorial, with vaginal child birth, advancing age, and increasing body-mass index as the most consistent risk factors.
\end{abstract}

Uterine prolapse was observed in a 65-year-old patient, about 20 $\mathrm{cm}$ inferiorfrom introitus, She wasmorbidly obese, constipated and had a disease, such as asthma, that causes an increase in intra-abdominal pressure. Traditional methods, including a vaginal hysterectomy, cystorectocele, perineomhaphy and McCall culdoplasty operations were successfully applied instead of a reconstructive vaginal mesh procedure. The patient also had cystocele, rectocele and enterocele. The patient's medical history was considered in making a decision on this a p proach. This case study has shown that using traditional vagina hysterectomy in some cases may be a more suitable approach than vaginal mesh because it sometimes causes severe complic ations.

The approach for Pelvic organ prolapse surgery should be chosen by considering the patient's condition, overlapping pathologies, and the surgeon's experience.

This study was presented at the 10th National Obstetrics and Gynecology Congress, 9-13 May 2012, Antalya, Turkey.

\section{Introduction}

Pelvic organ prolapse (POP) is the downward shift of pelvic organs, resulting in protrusion of the vagina, uterus or both. POP is a problem usually seen in older women and affects quality of life significantly. According to the classification system of pelvic organ prolapse developed by International Continence Society, patients are classificated in 4 stages- without pelvic organ prolapse- stage 0 , the most distal portion has descended $1 \mathrm{~cm}$ above the hymen- stage 1 , the most distal portion has descended $1 \mathrm{~cm}$ below or above the hymenstage 2 , the most distal portion has descended more than $1 \mathrm{~cm}$ below the hymen- stage 3 , all the lower urogenital system is outside- stage 4 [1]. Today, stage 1 and 2 cases are common, stage 3 is rarely seen, and stage 4 cases are very uncommon [2]. A population-based study of 1004 female patients revealed that $24 \%$ of cases were in Phase 0 , $38 \%$ in Phase 1, 35\% in Phase 2 and 2\% were in Phase POP [3]. POP surgery aims to reconstruct the anatomic damage and repair bladder, bowel and sexual function. Moreover, the object of POP surgery is also to raise patients' satisfaction and life standard and prevent possible complications. A variety of abdominal and vaginal approach procedures were defined in POP surgery. Mesh is applied in some approaches, whilst natural tissue is used in others. We have purposed to present a stage 4 POP case, who had applied to various centers,

\section{Journal of}

\section{Andrology \& Gynaecology}

\author{
Ayşe Ender Yumru ${ }^{1}$, Murat Bozkurt ${ }^{2 *}$, Burcu \\ Dincgez ${ }^{1}$, Banu Ondes ${ }^{1}$, Berker Kavsi ${ }^{1}$ and Cengiz \\ Yumru3 \\ ${ }^{1}$ Taksim Education and Research Hospital, Department of Obstetrics \\ and Gynecology, Istanbul, Turkey \\ ${ }^{2}$ Kafkas University School of Medicine, Department of Obstetrics \\ and Gynecology, Kars, Turkey \\ ${ }^{3}$ Taksim Education and Research Hospital, Department of \\ Anesthesiology and Critical Care, Istanbul, Turkey
}

\section{*Address for Correspondence}

Dr. Murat Bozkurt, MD, Assistant Professor, Kafkas University School of Medicine, Department of Obstetrics and Gynecology, KARS, TURKEY; Tel: 904742251150/4503- 905322279072 ; Fax: 904742251193; E-mail: jindrmb@yahoo.com

Submission: 30 April 2014

Accepted: 30 May 2014

Published: 02 June 2014

and whose treatment was delayed because of an inability to treat. This case study also addressed that the use of vaginal hysterectomy, in some cases, may be more advantageous then vaginal mesh. It also pointed out that applying a mesh procedure is not a purely harmless approach, and may cause a variety of severe complications.

\section{Case Report}

The 65-year-old, morbidly obese, G2 P2 patient applied to our clinic with the complaint of a palpable and growing mass from the vagina for 2 years. The patient did not have any special features in her medical history except for asthma, hypertension and chronic constipation due to thyroid dysfunction. The gynecological history of the patient included a large baby and forced birth. She had been in menopause for 25 years. Her general status was good, blood pressure was $140 / 80 \mathrm{mmHg}$, pulse was 76 beats $/ \mathrm{min}$. Upon gynecological examination, it was observed that the anterior wall of the vagina (cystocele), bladder, uterus, vaginal posterior wall (rectocele), and enterocele prolapsed out approximately $20 \mathrm{~cm}$ from introitus. The patient was classified stage 4 POP, and surgery was planned (Figure 1). Vaginal hysterectomy, cyctorectocele operation, perineorrhaphy, and McCall culdoplasty were performed on the patient. The use of mesh was not considered because there is limited data in our country for using mesh, the patient's age and general condition, and the complications of mesh (erosion, infection, rejection, dyspareunia, stricture, severe pain). The patient's urinary catheter was removed on the postoperative $2 \mathrm{rd}$ day, and the patient was discharged after recovery on the postoperative 3th day. The patient's appearance is shown in Figure 2 on postoperative 10 th day.

\section{Discussion}

Pelvic organ prolapse is the downward descent of the female pelvic organs, including the bladder, uterus or post-hysterectomy vaginal cuff, and the small or large bowel, resulting in protrusion of the vagina, uterus, or both. Prolapse development is multifactorial, with vaginal child birth, advancing age, and increased body-mass 


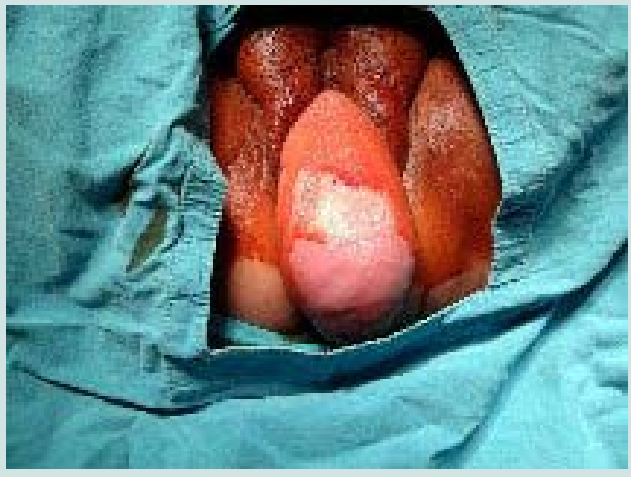

Figure 1: Stage 4 Pelvic organ prolapse, preoperative.

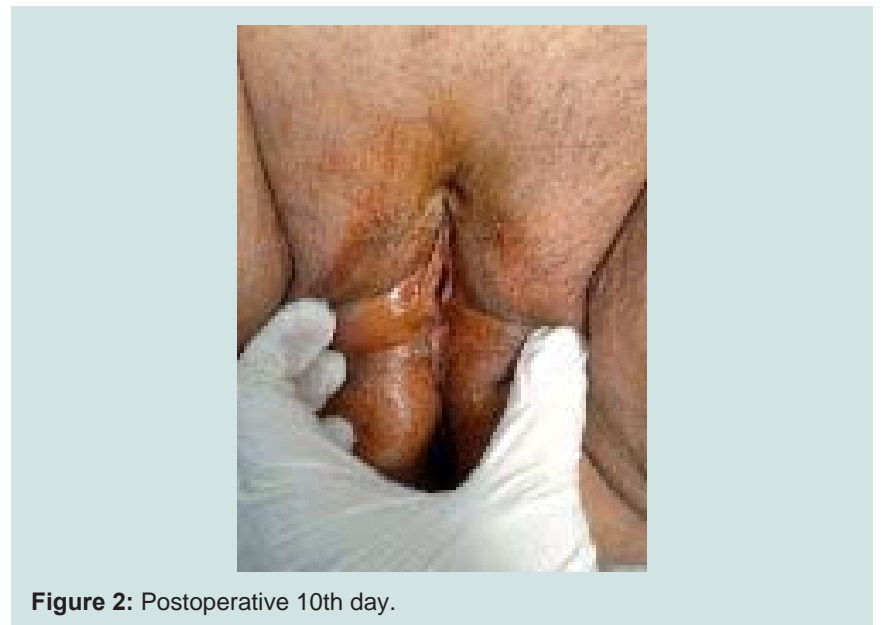

index as the most consistent risk factors.

The incidence of POP has been raised by an increase in the aging population. There is consensus that POP is an important medical issue. The risk of having POP surgery throughout the life of female has been determined as $11.1 \%$ in a study from the USA [4]. This risk rate has recently reached a peak of $19 \%$, revealed in a study from Australia [5].

Traditional surgical treatment of POP includes vaginal hysterectomy and anterior-posterior repair in patients with vaginal defects. The currently popular reconstructive surgery with vaginal mesh is an alternative approach in POP treatment. The organ protective feature of the synthetic mesh has made it a popular approach and has been used for more than 10 years.

The Food and Drug Administration (FDA) first approved the use of synthetic mesh designed for POP treatment in 2001. However, biological grafts have been used in abdominal surgical treatments of POP since 1970 [6]. Moreover, the transvaginal use of absorbable or permanent synthetic mesh to treat POP started after 2001. Mesh application in POP treatment became popular and preferred by patients and clinicians because of its surgical feature that protects organs. The pressure on clinicians, generated by companies that produce medical devices, is another factor for the rising use of mesh. Nevertheless, in some cases the application of vaginal mesh is a harmful procedure. The Database of Manufacturer and User Device
Experience in Medical device reports exhibited that the frequency of complications caused by mesh surgery is high and also severe in some cases. The FDA addressed this issue and published a "Social health notification form" in 2008 to inform clinicians on how to reduce unwanted complications and give required advice to patients [6]. This issue becomes more severe when considering that some or maybe most of the complications developing secondary to the use of vaginal mesh for POP and pelvic base dysfunction are not reported $[7,8]$.

A variety of complications might be observed due to the application of vaginal mesh in POP surgery. Rare but severe complications were defined in the MAUDE database [9]. These include death, fistula formation, and mesh erosion and exposition on different organs. Seven deaths were reported by the FDA in 2011. Three out of the seven were found to be directly associated with the application of mesh. Moreover, in two of the seven intestinal perforations were observed, whereas one out of the seven resulted in haemorrhage. Visceral vessel injury, intra-bladder haematoma, and mesh exposition on different organs such as the vagina, bladder or rectum are other important complications [10-12].

$\mathrm{H}$. Abed et al. analysed 110 cases that had vaginal mesh application for POP treatment and reported overall mesh erosion as $10.3 \%$, in an original systemic review published in 2008 [13]. Dyspareunia rate was determined to be $9.1 \%$ in the same study [13], whilst the rate was reported as 19\% in Weber's series [14]. Mesh construction and dysfunction of inferior urinary tract are other defined complications of vaginal mesh application for POP. Another important problem encountered post-mesh surgery is a recurrence of POP at a rate of $6-29 \%$ reported in a variety of series $[15,16]$. The rate of POP recurrence was determined to be higher in the younger age group and in cases with advanced prolapse [16]. Surgeons should be educated in this special surgical procedure of mesh application and define complications and repair defects. Patients should be informed about the permanent complications of mesh use, and a confirmation of the acceptance of treatment should be required. Surgeons and patients should decide on an operation after considering the pros and cons of it [17].

Furthermore, the total cost of the mesh kit and its surgery is considerably higher than the traditional surgical procedure, a vaginal hysterectomy, in developing countries like Turkey. The vaginal hysterectomy, a conventional surgical approach, was chosen with the approval of our patient, 65 years of age, considering high risk factors of the recurrence of POP including advance prolapse, overlapping cystocele and rectocele, asthma and a history of chronic constipation. There were also other defined risk factors including morbid obesity and a history of forced birth. To reduce the risk of recurrence of POP, such as a vaginal cuff prolapse, consultations were requested from the endocrine clinic, to eliminate constipation due to hypothyroidism, and from a clinic for chest disease for asthma. Both conditions: constipation and asthma, increase intra-abdominal pressure. Moreover, the patient also consulted with an endocrinologist and a dietitian for morbid obesity. The changes required in her lifestyle were discussed in detail with the patient. Although stage 4 POP is very rare today, it disrupts quality of life in an extreme way. Therefore, selection of appropriate treatment is very important [18]. While the use of mesh during surgery is increasing, it brings about some 
Citation: Yumru AE, Bozkurt M, Dincgez B, Ondes B, Kavsi B, Yumru C. Can Vaginal Hysterectomy be Left for the Treatment of Advanced Stage of Pelvic Organ Prolapse? J Androl Gynaecol. 2014;2(1): 3.

intraoperative and postoperative complications that are discussed above in the text $[18,19]$. Using mesh for select patients is successful, but today, except in clinical trials, there isn't data available to support the routine use of mesh [20]. Because there is not sufficient data about the use of mesh and its complications, it is emphasized that the classical approach is more appropriate than the use of mesh for some cases.

\section{Conclusion}

To conclude, when deciding on the surgical approach, either vaginal hysterectomy, a conventional surgery, or application of vaginal mesh, a popular method of organ protective surgery, the patient's medical condition should be considered, in addition to overlapping pathologies and the surgeon's experience.

\section{References}

1. Persu C, Chapple CR, Cauni V, Gutue S, Geavlete P (2011) Pelvic Organ Prolapse Quantification System (POP-Q) - a new era in pelvic prolapse staging. J Med Life 4: 75-81.

2. Manonai J, Mouritsen L, Palma P, Contreras-Ortiz O, Korte JE, et al. (2011) The inter-system association between the simplified pelvic organ prolapse quantification system (S-POP) and the standard pelvic organ prolapse quantification system (POPQ) in describing pelvic organ prolapse. Int Urogynecol J 22 : 347-352

3. Swift S, Woodman P, O'Boyle A, Kahn M, Valley M, Bland D, et al. (2005) Pelvic Organ Support Study (POSST): the distribution, clinical definition, and epidemiologic condition of pelvic organ support defects. Am J Obstet Gynecol 192:795-806.

4. Olsen AL, Smith VJ, Bergstrom JO, Colling JC, Clark AL (1997) Epidemiology of surgically managed pelvic organ prolapse and urinary incontinence. Obstet Gynecol 89: 501-506.

5. Smith FJ, Holman CD, Moorin RE, Tsokos N (2010) Lifetime risk of undergoing surgery for pelvic organ prolapse. Obstet Gynecol 116:1096-1100.

6. Food and Drug Administration, 2011, FDA Safety Communication: UPDATE on Serious Complications Associated with Transvaginal Placement of Surgical Mesh for Pelvic Organ Prolapse, FDA, Silver Spring, Md, USA.

7. Deng DY, Rutman M, Raz S, Rodriquez LV (2007) Presenting and management of major complications of mid-urethral slings: are complications under- reported. Neurourol Urodyn $26: 46-52$
8. Costantini E, Lazzeri M, Porena M (2007) Managing complications after midurethral sling for stress urinary incontinence. EAU-EBU Update Series 5 : 232- 240.

9. http://www.accessdata.fda.gov/scripts/cdrh/cfdocs/cfmaude/search.cfm

10. Ignjatovic I, Stosic D (2007) Retrovesical haematoma after anterior Prolift procedure for cystocele correction. Int Urogynecol J Pelvic Floor Dysfunct 18 1495-1497.

11. Yamada BS, Govier FE, Stefanovic KB, Kobashi KC (2006) Vesicovagina fistula and mesh erosion after Perigee (transobturator polypropylene mesh anterior repair). Urology 68: 1121.e5-7.

12. Sung VW, Rogers RG, Schaffer JI, Balk EM, Uhlig K, et al. (2008) Graft use in transvaginal pelvic organ prolapse repair: a systematic review. Obstet Gynecol 112:1131-1142.

13. Abed H, Rahn DD, Lowenstein L, Balk EM, Clemons JL, et al. (2011) Incidence and management of graft erosion, wound granulation, and dyspareunia following vaginal prolapse repair with graft materials: a systematic review. Int Urogynecol J 22: 789-798.

14. Weber AM, Walters MD, Piedmonte MR (2000) Sexual function and vaginal anatomy in women before and after surgery for pelvic organ prolapse and urinary incontinence. Am J Obstet Gynecol 182: 1610-1615.

15. Blandon RE, Bharucha AE, Melton LJ 3rd, Schleck CD, Babalola EO, et al (2007) Incidence of pelvic floor repair after hysterectomy: A population-based cohort study. Am J Obstet Gynecol 197: 664.e1-7.

16. Whiteside JL, Weber AM, Meyn LA, Walters MD (2004) Risk factors for prolapse recurrence after vaginal repair. Am J Obstet Gynecol 191:15331538.

17. Ellington DR, Richter HE (2013) Indications, contraindications, and complications of mesh in surgical treatment of pelvic organ prolapse. Clin Obstet Gynecol 56: 276-288.

18. Detollenaere RJ, den Boon J, Stekelenburg J, Alhafidh AH, Hakvoort RA et al. (2011) Treatment of uterine prolapse stage 2 or higher: a randomized multicenter trial comparing sacrospinous fixation with vaginal hysterectomy (SAVE U trial). BMC Women's Health $15: 11-14$

19. Nguyen JN, Jakus-Waldman SM, Walter AJ, White T, Menefee SA (2012) Perioperative complications and reoperations after incontinence and prolapse surgeries using prosthetic implants. Obstet Gynecol 119: 539- 546.

20. Miller D, Lucente V, Babin E, Beach P, Jones P, et al. (2011) Prospective clinical assessment of the transvaginal mesh technique for treatment of pelvic organ prolapse-5-year results. Female Pelvic Med Reconstr Surg 17: 139143
Copyright: @ 2014 Yumru AE, et al. This is an open access article distributed under the Creative Commons Attribution License, which permits unrestricted use, distribution, and reproduction in any medium, provided the original work is properly cited. 